\title{
Estrutura de Lewis e Geometria Molecular...
}

...mas não necessariamente por essa ordem!

MÁRIO VALEN T E*, HELENA MOREIRA

Os alunos mostram frequentemente dificuldades na previsão de geometrias moleculares, até para moléculas muito simples. Estas dificuldades estão, muitas vezes, ligadas com a determinação prévia da correspondente estrutura de Lewis (ou da fórmula estrutural), que é usualmente tida como ponto de partida essencial para a referida previsão. Apresenta-se, neste artigo, um modo fácil de prever a geometria molecular de uma molécula simples, envolvendo elementos representativos - constituida por um átomo central e vários átomos ou pares de electrões não partilhados em seu redor - e que serve de ponto de partida para a determinação posterior da correspondente fórmula estrutural da molécula, que auxiliará na previsão das ordens de ligação.

\section{Introdução}

A geometria molecular é um parâmetro de importância fundamental para a previsão da polaridade de uma molécula. Esta, por sua vez, permite inferir sobre o tipo e intensidade das interacções intermoleculares que se podem estabelecer entre moléculas no composto puro, ou com átomos, ou moléculas de outras substâncias. Contudo, a previsão da geometria molecular, até de moléculas simples, representa frequentemente um problema que muitos alunos do ensino secundário e, por vezes do superior, não conseguem superar [1, 2, 3]. Estas dificuldades estão usualmente relacionadas com a suposta necessidade de determinar, previamente, a estrutura de Lewis (ou a fórmula estrutural) para as moléculas. De facto, é frequente em livros de texto de todos os níveis, assumir-se que a previsão da geometria molecular é posterior à determinação da estrutura de Lewis. Ora, não é necessariamente assim [4]...

Para o caso de moléculas pequenas (neutras ou iónicas), envolvendo elementos representativos, constituídas por um átomo central e vários átomos pe-

Colégio D. Duarte, Rua Visconde de Setúbal, 86, Porto, 4200-497, Portugal

( E-mail: madmage1@yahoo.com) riféricos pode-se, com vantagem, inverter o processo acima mencionado, de forma a prever a geometria molecular e, posteriormente, tomar o resultado como ponto de partida para a determinção da correspondente fórmula estrutural, eliminando algumas das dificuldades apresentadas pelos alunos.

\section{Previsão de geometrias moleculares}

A geometria de uma molécula pode ser determinada, de acordo com o método proposto, da seguinte forma:

(1) Procede-se à contagem do número total de electrões de valência presentes numa molécula, que corresponde ao número total dos electrões de valência dos átomos participantes, tendo, no entanto, atenção à carga. Numa molécula catiónica (por exemplo, no nitrónio, $\mathrm{NO}_{2}^{+}$), cada carga positiva corresponde à saida de um electrão de valência, e numa molécula aniónica (por exemplo, no nitrito, $\mathrm{NO}_{2}^{-}$), cada carga negativa corresponde à entrada de um electrão de valência na contagem. Este passo não é difícil de dominar pelos alunos, na medida em que se relaciona com facilidade o número de electrões de valência de cada átomo com o grupo em que se este se encontra no Quadro de Classificação Periódica.

(2) Define-se qual o átomo central, que é, usualmente, o menos electronegativo (à excepção do hidrogénio que, em circunstâncias normais, não pode ser 0 átomo central). Podem surgir dificuldades quando todos os átomos são iguais (por exemplo, no ozono, $\mathrm{O}_{3}$ ), e então qualquer um deles poderá ser considerado o central e os outros serão periféricos, ou em algumas excepções (por exemplo, no óxido de dicloro, $\mathrm{Cl}_{2} \mathrm{O}$ ) para as quais o átomo (ligeiramente) mais electronegativo é o central.

(3) Determina-se o número total de electrões dos átomos periféricos, considerando que têm a sua camada de valência completamente preenchida. $\mathrm{Na}$ prática, esta contagem resume-se simplesmente a dois electrões para cada átomo de hidrogénio e oito electrões para cada átomo de qualquer outro elemento.

(4) Calcula-se o número de electrões não partilhados pertencentes ao átomo central, que corresponde à diferença entre o número total de electrões de valência presentes na molécula (determinado no primeiro passo) e o número total de electrões dos átomos periféricos, considerando que têm a sua camada 
de valência completamente preenchida (determinado no terceiro passo).

(5) Por fim, usa-se o modelo de Repulsão dos Pares Electrónicos da Camada de Valência, de Gillespie [5,6,7] (ver Tabela 1 e Nota 1), tomando os pares electrónicos não partilhados pertencentes ao átomo central como domínios electrónicos não ligantes e o número de ligações entre o átomo central e os átomos periféricos, independentemente da sua ordem de ligação, como domínios ligantes (e igual ao número de átomos periféricos).

É apresentado, de seguida, um exemplo de aplicação para a espécie molecular aniónica $\mathrm{NO}_{2}^{-}$.

(1) O número total de electrões de valência é: $5+2 \times 6+1=18$,

(2) O átomo central é o de azoto,

(3) O número total de electrões dos átomos periféricos (correspondente a dois átomos de oxigénio) é: 2 × $8=16$ electrões,

(4) O número de electrões não partilhados pertencentes ao átomo central é: 18 - $16=2$, isto é, um par electrónico não ligante, ou um domínio não ligante,

(5) Com dois átomos periféricos (dois domínios ligantes) e um par electrónico não ligante (domínio não ligante) a molécula apresenta uma geometria angular (Figura 1).

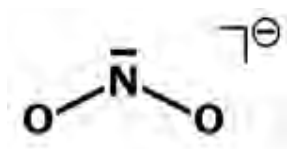

Figura 1 Esquema da molécula $\mathrm{NO}_{2}{ }^{-}$, com a representação dos três domínios electrónicos que the definem directamente a geometria.

\section{Determinação da fórmula estrutural}

Partindo da geometria molecular, determinada pelo método acima descrito, consideram-se numa primeira fase todos os domínios ligantes rodeando o

Tabela 1 Geometrias adoptadas em função do número e tipo de domínios electrónicos que rodeiam o átomo central (\# DEL: $n .{ }^{\circ}$ de domínios electrónicos ligantes; \# DENL: $n .{ }^{\circ}$ de domínios electrónicos não ligantes; \# TDE: $n .{ }^{\circ}$ total de domínios electrónicos).

\begin{tabular}{|c|c|c|c|c|}
\hline \# DEL & \# DENL & \# TDE & geometria de base & geometria efectiva \\
\hline 2 & 0 & 2 & linear & linear \\
\hline 2 & 1 & \multirow{2}{*}{3} & \multirow{2}{*}{ triangular plana } & angular $\left(\sim 120^{\circ}\right)$ \\
\hline 3 & 0 & & & triangular plana \\
\hline 2 & 2 & \multirow{3}{*}{4} & \multirow{3}{*}{ tetraédrica } & angular $\left(\sim 109^{\circ}\right)$ \\
\hline 3 & 1 & & & piramidal trigonal \\
\hline 4 & 0 & & & tetraédrica \\
\hline 2 & 3 & \multirow{4}{*}{5} & \multirow{4}{*}{ bipiramidal trigonal } & linear \\
\hline 3 & 2 & & & em T distorcido \\
\hline 4 & 1 & & & bisfenóide \\
\hline 5 & 0 & & & bipiramidal trigonal \\
\hline 2 & 4 & \multirow{5}{*}{6} & \multirow{5}{*}{ octaédrica } & linear \\
\hline 3 & 3 & & & em T distorcido \\
\hline 4 & 2 & & & quadrada plana \\
\hline 5 & 1 & & & piramidal quadrada \\
\hline 6 & 0 & & & octaédrica \\
\hline
\end{tabular}

átomo central como sendo constituídos por pares electrónicos.

Para obter a fórmula estrutural da molécula procede-se da seguinte forma:

1. Associam-se equitativamente os electrões de valência ainda não distribuídos, pelos átomos periféricos.

2. Determinam-se as cargas formais de todos os átomos presentes na molécula, isto é, calcula-se a diferença entre o número de electrões que tornariam o átomo neutro e o número de electrões que ele possui na presente estrutura, que corresponde à soma de metade do número de electrões envolvidos em domínios ligantes com o número de electrões presentes nos seus domínios não ligantes.

3. Deslocam-se pares electrónicos de domínios não ligantes dos átomos periféricos para domínios ligantes, tentando anular-se, ou nessa impossibilidade, minimizar-se a carga formal do átomo central [8] (ver Nota 2) ou seja, quando não for possível anular a carga formal do átomo central por este não poder suportar mais de quatro pares electrónicos em seu redor (como é o caso dos elementos carbono, azoto, oxigénio e flúor), deve-se então reduzi-la ao mínimo permitido pela regra do octeto.

Quando o modo de minimizar a carga formal do átomo central se pode conseguir de várias formas equivalentes, a molécula apresenta híbridos de ressonância, isto é, várias estruturas contribuíntes, e para as ligações cuja ordem pode variar teremos um carácter intermédio.

Tomando como exemplo a espécie $\mathrm{NO}_{2}{ }^{-}$, cuja geometria molecular já foi acima determinada, passa-se à escrita da correspondente fórmula estrutural: 


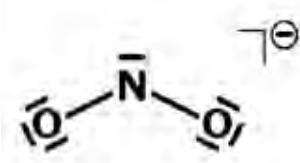

(a)

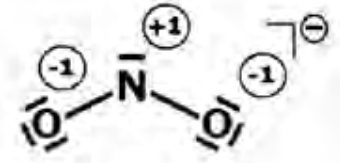

(b)

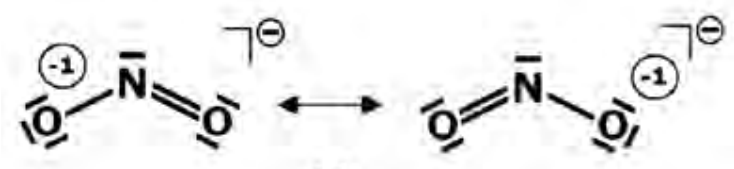

(c)

Figura 2 Passos seguidos para a escrita da fórmula estrutural correspondente à espécie $\mathrm{NO}_{2}{ }^{-}$.

(1) Distribuem-se os $18-6=12$ electrões pelos dois átomos periféricos de oxigénio (Figura 2 a),

(2) Determinam-se as cargas formais de todos os átomos (Figura 2 b),

(3) Minimiza-se carga formal do átomo central (Figura $2 \mathrm{c}$ ).

Verifica-se, neste exemplo, a existência de duas fórmulas estruturais equivalentes (Figura 2 c) o que indica a existência de ressonância entre elas e, portanto, nesta espécie (anião nitrito) verifica-se uma ligação azoto-oxigénio de ordem intermédia entre a simples e a dupla.

\section{Conclusões}

Este método apresenta a vantagem de ser simples e sequencial, o que permite a um aluno prever a geometria de uma molécula simples envolvendo elementos representativos e, posteriormente, a respectiva fórmula estrutural. Saliente-se ainda que se torna possível estimar ângulos de ligação a partir do número e tipo de domínios ligantes e não ligantes que rodeiam o átomo central. Ao longo do processo o aluno vê-se confrontado com a noção de carga formal e com a possibilidade de ocorrência de ressonância.

A desvantagem deste método centra-se na dificuldade da aplicação a moléculas com várias possibilidades de escolha para átomos centrais. Contudo, no cômputo geral, pode considerar-se uma boa ferramenta inicial na previsão de geometrias moléculares (e, posteriormente, das correspondentes fórmulas estruturais) para a maioria das moléculas simples, envolvendo elementos representativos, o que auxilia na aquisição e estabilização de conceitos importantes como geometria molecular, modelo de repulsão dos pares electrónicos da camada de valência, carga formal e ressonância.

\section{Notas}

1. O modelo de Gillespie nas suas versões mais recentes envolve a noção de domínio electrónico, que consiste numa região do espaço onde há elevada probabilidade de encontrar um ou mais pares de electrões. Também no presente método se pode considerar cada par de electrões não ligantes, bem como cada ligação (independentemente da sua ordem formal) entre o átomo central e um átomo periférico, como um domínio electrónico.

2. A minimização das diferenças de cargas formais entre os átomos nas estruturas de Lewis (e fórmulas estruturais) tem sido considerada, em muitos artigos [8] e livros de texto [9], como originando representações mais próximas da realidade da molécula. No entanto, também há quem privilegie a obediência à regra do octeto [10], ba- seando-se em cálculos teóricos que apontam para uma muito baixa contribuição de orbitais $\boldsymbol{d}$ para a ligação em moléculas onde o átomo central estaria rodeado por mais do que oito electrões, e para a possibilidade de se verificarem ligações polielectrónicas, pluricêntricas [11].

Referências

1. J.P. Birk, M.J. Kurtz, Journal of Chemical Education, 76 (1999) 124-128

2. C. Furio, M.L. Calatayud, Journal of Chemical Education, 73 (1996) 36-41

3. V.M.M. Lobo, Química (Boletim da Sociedade Portuguesa de Química) 70 (1998) 13-17

4. M. Valente e H. Moreira, Livro de Resumos do $4 .^{\circ}$ Encontro da Divisão de Educação e Ensino da Química (2005) 79-80

5. R.J. Gillespie, Journal of Chemical Education, 81 (2004) 298-304

6. R.J. Gillespie, E.A. Robinson, Angewandte Chemie International Edition in English, 33 (1996) 495-514

7. R.J. Gillespie, Chemical Society Reviews, 21 (1992), 59-69

8. G.H. Purser, Journal of Chemical Education, 78 (2001) 981-983; J.Q. Pardo, Journal of Chemical Education, 66 (1989) 456-458; J.A. Carrol, Journal of Chemical Education, 63 (1986) 28-31

9. G.L. Miessler e D.A. Tarr, Inorganic Che-

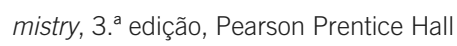
(ed.), Nova Jérsia, 2004; D.F. Schriver, P.W. Atkins e C.H. Langford, Inorganic Chemistry, 2. ${ }^{\text {a }}$ edição, Oxford University Press (ed.), Oxónia, 1998; R. Chang, Química, 5. ${ }^{a}$ edição, McGraw Hill (ed.), Lisboa, 1994

10. L. Suidan, J.K. Badenhoop, E.D. Glendenring e F. Weinhold, Journal of Chemical Education, 72 (1995) 583-586

11. O.W. Curnow, Journal of Chemical Education, 75 (1998) 910-915 